\title{
A vida cotidiana da escola expressa um cotidiano? Aproximações ontológicas em debate
}

\author{
Patrícia Laura Torriglia* \\ Margareth Feiten Cisne**
}

\section{Resumo}

O presente texto, de natureza teórico conceitual, discute, a partir da ontologia crítica, a produção de conhecimento, os processos de conhecer, ensinar e aprender, bem como as bases ontológicas que consolidam tais processos. A partir de nossos estudos baseados na perspectiva do materialismo histórico-dialético - Lukács, Rubinstein Sheptulin e Heller - e do trabalho de formação que viemos desenvolvendo junto ao Grupo de Estudos e Pesquisa em Ontologia Critica - GEPOC, defendemos como premissa preliminar a preexistência do mundo objetivo independente de nossa consciência, o que implica considerá-lo como possuidor de uma base material que o sustenta e permite, por meio dessa materialidade, que é processual e histórica, estabelecer um conhecimento objetivo sobre si, isto é, uma inteligibilidade do mundo. Nesta direção, em um primeiro momento, abordaremos algumas questões sobre o conhecimento e seu processo de apropriação a partir da base supracitada. Posteriormente, aprofundaremos o conceito de cotidiano escolar e de vida cotidiana, seus conteúdos e sua forma de transmissão e apropriação de conhecimentos, e a relação com a didática. Finalizaremos apresentando questões que nos possibilitem novas investigações.

Palavras-chave: Vida cotidiana. Apropriação do conhecimento. Ontologia crítica.

\footnotetext{
"Doutora em Educação pela Universidade Federal de Santa Catarina (UFSC). Professora do Departamento de Estudos Especializados em Educação da Universidade Federal de Santa Catarina (UFSC).

** Doutora em Educação pela Universidade Federal de Santa Catarina (UFSC). Professora do Núcleo de Desenvolvimento Infantil da Universidade Federal de Santa Catarina (UFSC).
}

PERSPECTIVA, Florianópolis, v. 35, n. 3, p. 996-1012, jul./set.. 2017 http://www.perspectiva.ufsc.br 


\section{Introdução}

A partir da ontologia crítica, o presente texto discute a produção de conhecimento, os processos de conhecer, ensinar e aprender e as bases ontológicas envolvidas nos processos de apropriação do conhecimento, com o intuito de compreender a relação entre o cotidiano escolar e a vida cotidiana. Nesse sentido, defendemos algumas premissas, entre elas, neste primeiro momento, a preexistência do mundo objetivo independente de nossa consciência, o que implica considerar que o mundo possui uma base material que o sustenta e permite, por meio dessa materialidade que é processual e histórica, estabelecer um conhecimento objetivo sobre si, isto é, uma inteligibilidade sobre esse mundo.

Essa consideração nos leva a outra premissa, a de que para compreender a realidade a partir de uma perspectiva ontológica ${ }^{1}$ é necessário, como diz Lukács (1978, p. 2), considerar que "todo existente deve ser sempre objetivo, ou seja, deve ser sempre parte (movente e movida) de um complexo concreto". Isso, segundo o autor, traz duas consequências importantíssimas: primeira, como já apontamos acima, o ser e tudo que o envolve são vistos como processo histórico; segunda, as categorias não são vistas simplesmente como "algo que é ou se torna", mas como formas de ser, determinações da sua própria existência e, portanto, o movimento da história dessa existência.

Desse modo, é importante reconhecer que, nos processos de conhecer e apreender, estarão sempre envolvidas relações e movimentos internos singulares - desenvolvimento da psique - que se configuram a partir da relação com o mundo externo, no qual os seres humanos se objetivam, valorizam-se e apropriam-se dos instrumentos da cultura em um determinado momento histórico, procurando - não sem contradições - reproduzir $^{2}$ e produzir sua existência. Portanto, estabelecer relação é uma atividade realizada por um sujeito objetivado e subjetivado (e vice-versa), ocorrendo, consequentemente, dois movimentos (externo e interno) dinâmicos e constantes, que possuem uma interdependência. Nas palavras de Rubinstein (1979, p. 286), "é uma atividade com a qual o organismo responde à ação do estímulo, porém, o estímulo externo não determina de forma direta o efeito último do processo a que dá origem, sua ação se efetua de maneira mediada através das condições em que se encontra".

Esse fato é de capital importância e se torna vital explicitá-lo, já que defendemos uma ontologia crítica - materialista e dialética - da concepção de mundo, tentando evitar as dicotomias tão correntes em perspectivas pragmáticas, idealistas, pós-modernas ${ }^{3}$, dentre outras vertentes. Explicitar a diferença 
que temos em relação a estas perspectivas torna-se necessário, porque, a partir de nossos estudos e de nossas investigações ${ }^{4}$, percebemos a existência de certa imprecisão em relação ao complexo educacional no que tange às relações de conhecimento, que nos possibilitam, entre outras questões, realizar aquilo que Lukács (2013) considera um "correto espelhamento do real", isto é, uma correta apreensão da realidade.

Sendo assim, a partir do exposto, apresentaremos primeiramente alguns subsídios sobre o conhecimento e a sua apropriação a partir de uma base ontológica. Posteriormente, aprofundaremos os conceitos de cotidiano escolar e vida cotidiana, seus conteúdos, suas formas de apropriação, suas formas de transmissão e suas relações com a didática. Para finalizar, apresentaremos duas grandes questões de pesquisa que delineiam a proposição de nossos processos de investigação ulteriores.

\section{Conhecimento e processo de conhecer o mundo objetivo: base ontológica para uma compreensão do ensino e da didática}

Já explictamos em outro contexto ${ }^{5}$ que o conhecimento, em seu sentido amplo, é imprescindível para compreensão da existência, além de ser parte fundamental do trabalho - atividade vital - de constante troca entre os seres humanos e a natureza. Nos processos de apropriação e objetivação do mundo objetivo, conhecer as propriedades e legalidades dos fenômenos é fundamental para a transformação e reprodução da vida.

Como explica Sheptulin (1983, p. 7), “[...] a natureza metódica é a característica imprescindível do modo de vida humana, da atividade orientada a um fim". Essa atividade, que requer certo grau de sistematização e generalização por parte do sujeito pensante - especificidade do ser social -, pressupõe, por meio do trabalho, uma relação constante com a cadeia de causalidades existentes no real e o estabelecimento de finalidades que permitam ao sujeito, no processo de conhecimento, compreender e capturar, por meio da atividade do pensamento, o mundo objetivo, para poder efetivar a finalidade pensada.

Reiteramos: o pensamento é uma atividade em movimento (processo) que se objetiva e é objetivado, ou seja, é formado, segundo Rubinstein (1966, p. 22), por influências recíprocas entre o sujeito pensante e o objeto, "entre este e o conteúdo objetivo do problema que se resolve". Isso implica, necessariamente, considerar que esse processo possui um movimento progressivo e, ao mesmo 
tempo, contraditório. Significa também, entre outras coisas, que existem graus, dimensões de elaborações internas (análises, sínteses, generalizações e abstrações) ${ }^{6}$ que compõem essa atividade do pensar e que movimentam, no processamento desses elementos, conhecimentos novos e conhecidos, velhos e renovados, já que a apropriação não é uma linha direta ou de mão única, ela é também movimento que incorpora (vai incorporando) constantemente os conhecimentos que se apresentam na cotidianidade dos sujeitos.

Essa possibilidade de apropriação do conhecimento do mundo precisa ser compreendida em um sentido amplo, a partir da atividade vital ontológica (trabalho em geral), que expande e amplia a humanização do homem. Esse processo é ineliminável, como ineliminável é a complexificação das relações sociais, construindo desta forma o processo histórico da existência do ser social. Isto significa uma nova forma de existência, diferente do ser inorgânico e orgânico, portanto, de um ser agora social $^{7}$ capaz de produzir e reproduzir sua vida de maneira criativa e consciente, planejando e procurando entender/explicar o acontecer dos fenômenos (cadeia de causalidades e casualidades) da vida em movimento, a fim de transformar o mundo circundante e ampliar, cada vez mais, os processos das objetivações humanas.

Todo esse movimento e esse processo se colocam como prioridade no embate das necessidades de produção e reprodução da existência, já que sem conhecer não poderíamos transformar nem a natureza nem a relação entre os seres humanos.

Nessa direção, partindo de uma concepção ontológica, o conhecer enquanto impulso vital é o que Lukács denomina - com subsídio nos estudos ontológicos de Nicolai Hartmann (1954) - de intentio recta, impulso ao conhecimento da realidade, captura da realidade mediante a consciência.

Assim, entende-se que a realidade pode ser conhecida por meio da consciência, isto é, por meio da atividade do reflexo exercida pelo pensamento para fins de apropriação dessa realidade, cuja uma das finalidades é "[...] o entendimento das causalidades efetivamente atuantes [que] compõe o campo da intentio recta e está vinculado ao desenvolvimento do conhecimento científico" (AGUIAR, 2011, p. 46). Assim, tendo em vista que esse impulso vital que induz o indivíduo a conhecer está também relacionado - e não poderia deixar de ser assim - às complexificações do desenvolvimento social da vida cotidiana, assim como "[...] da ciência e da filosofia, pode acontecer que o desenvolvimento social crie situações e direções que torcem e desviam essa intentio recta da compreensão do ser real" (LUKÁCS, 2013, p. 97). Diante dessa afirmação, acentua-se cada vez mais a necessidade da crítica 
ontológica baseada na práxis a partir da totalidade social e de sua orientação, como bem afirma Lukács (2013).

A partir do explicitado acima, concordamos com o autor no tocante ao cerne da questão ser a falsa suposição de que a ciência possa corrigir, em termos ontológicos - críticos corretos -, “[...] a vida cotidiana e a filosofia, as ciências, ou, de modo inverso, que a vida cotidiana possa desempenhar, nos confrontos com a ciência e com a filosofia, o papel da cozinheira de Molière"8 (LUKÁCS, 2013, p. 98). O que autor intenta demonstrar com sua reflexão é que inexiste uma forma certa, uma garantia de que mesmo a ciência ou a filosofia poderiam, a partir de suas explicações teóricas, de suas abstrações e considerações a respeito da realidade, corrigir os desvios que acontecem na vida cotidiana e, ao mesmo tempo, que ela - a vida cotidiana - tem seu próprio movimento de continuidade. Isso demarca ainda mais a necessidade de se ter presente a totalidade social, marcada pelo caráter desigual e dinâmico da realidade, tornando-se necessária, para tanto, uma crítica ontológica que permita o tratamento desse complexo problema entre a vida cotidiana, a ciência e a filosofia. Por isso, a crítica "[...] deve orientarse pelo conjunto diferenciado da sociedade - diferenciado concretamente em termos de classes - e pelas inter-relações dos tipos de comportamentos que daí derivam [...]" (LUKÁCS, 2013, p. 98). Enfim, acentuar a função da práxis como critério da teoria é decisivo, segundo Lukács, para qualquer desenvolvimento espiritual e para qualquer práxis social, haja vista que

[...] toda práxis se orienta imediatamente no sentido de alcançar um objetivo concreto determinado. Para tanto deve ser conhecida a verdadeira constituição dos objetos que servem de meio para tal posição de finalidade, pertencendo igualmente àquela constituição as relações, as prováveis consequências, etc. Por isso a práxis está inseparavelmente ligada ao conhecimento [...]. (LUKÁCS, 1984, p. 8).

Diríamos ainda mais: a práxis é sempre conhecimento, não poderia existir sem esse processo que se efetiva a partir da atividade humana, ou seja, por meio do trabalho e de todas as outras atividades que dele se desdobram. Nesse sentido, para Lukács (2013, p. 162), as diferentes formas de constituição da divisão do trabalho ao logo do processo histórico se entrecruzam, ocasionando diferenciações no modo de produzir e reproduzir a existência, das quais, historicamente, a mais importante é a diferenciação que leva o ser humano a produzir mais do que o necessário para se reproduzir, extrapolando assim a esfera da mera adaptabilidade. Essa tendência - de produzir mais do necessário - está também na intentio recta, que denota, como já mencionamos, o impulso de conhecer 
a realidade, responsável por levar os seres humanos a procurar e ampliar o mundo circundante. Deste processo de ampliação e conhecimento da realidade resultam as generalizações e as fixações, que surgem no processo de trabalho e em seus desdobramentos. Essas generalizações ${ }^{9}$ vão se aprimorando e adquirindo maior domínio das legalidades e dos meios para a realização de outros fins que, posteriormente, serão novamente parte de novas causalidades postas e de novos conhecimentos, expressos em um movimento continuum. Aqui repousa a gênese do processo de conhecimento.

Assim, reprodução e continuidade são marcas essenciais da existência da vida: reprodução dos seres singulares e da sociedade, desenvolvimento das subjetividades e do constante e ineliminável processo de objetivação, isto é, da objetividade das subjetividades que compõem o movimento do desenvolvimento ${ }^{10}$. Entretanto, cabe destacar que o processo de objetivação não é rígido ou estanque, ele é expressão da dinâmica do real e constitui a base para outros sistemas e objetivações superiores.

Nessa mesma direção, compondo o complexo inseparável da reprodução, também o complexo educacional, em seu sentido lato, acompanha a gênese do conhecimento (e vice-versa), porque nele se expressa a possibilidade concreta de sua fixação mediante as complexificações do ser social. De tal modo, com base em Lukács (2013), Torriglia (1999, p. 110) explica que

[...] -o mutismo natural do ser humano começa a diminuir e mediante a consciência de sua práxis se torna membro do gênero. O pertencer ao gênero (através do nascimento) se torna consciente por uma prática conscientemente social, mediante a educação em seu sentido lato.

A educação, em sua acepção mais stricta (sem perder essa dimensão mais ampla e essencial), está atrelada e atenta às demandas de seu tempo, e sua função existe em um movimento constante que permite e favorece a apropriação dos conhecimentos da humanidade. Educação e conhecimento são duas faces de uma mesma moeda na complexificação das relações sociais, quer dizer, na história da reprodução e produção da vida, já que toda a educação envolve uma relação de conhecimento.

A produção de conhecimento e o sentido de conhecer estão balizados a partir de uma compreensão de formação humana que implica uma oposição aos diferentes recuos teóricos já assinalados anteriormente ${ }^{11}$. Assim, recuperar um tipo de teoria que busca aprofundar os nexos e as estruturas do mundo objetivo, um sujeito inteligível e com possibilidade de expandir e ampliar sua personalidade, uma ideia diferente de compreensão da vida cotidiana, uma articulação entre 
epistemologia e ontologia com prioridade ontológica, entre outros desdobramentos, parece-nos premente e fundamental.

Essa breve síntese sobre o conhecimento, bem como sobre sua apropriação a partir de uma base ontológica, permite-nos elucidar algumas questões em relação ao campo educacional, especialmente à didática, complexo importantíssimo para compreensão da continuidade da produção, reprodução e transformação do conhecimento, processos que implicam diferentes formas de atividades e concepções sobre a práxis, em que, continuamente, realizamos escolhas e decisões, interagimos com o mundo objetivo e nos comprometemos - ou deveríamos nos comprometer - com as consequências que derivam dessas escolhas. Nessa compreensão, a formação humana inclui processos de educar, ensinar e aprender que não estão fora desse movimento, uma vez que, ao contrário, implicam sempre escolhas e, portanto, decisões em que certamente estarão sempre envolvidas, de forma consciente ou inconsciente, determinada orientação e concepção de como é o mundo - uma posição ontológica que, na maioria das vezes, não é consciente.

\section{Escola e vida cotidiana: algumas novas reflexões}

A partir do exposto anteriormente, consideramos necessário esclarecer o que entendemos por cotidiano escolar e vida cotidiana. Nessa perspectiva, cabe perguntar: existe alguma diferença entre eles? Acreditamos que sim. Entendemos que uma concepção de vida cotidiana não está atrelada e fixada aos limites da rotina ou de um nível menor da existência. Reiteramos: a vida cotidiana não é um nível de existência, ela é a existência em movimento, que precisa superar o reino das necessidades para atingir maiores graus de liberdade, ou seja, o que Marx denominou de reino da liberdade. Entendemos também que a vida cotidiana permeia a existência da totalidade social, porque é parte fundante das relações sociais, ela - a vida - tem, então, um cotidiano intrínseco à sua existência, que não se pode perceber ou entender como algo definido e fixo. Ao contrário, ela está em permanente movimento, já que se configura com o movimento das relações que se objetivam constantemente na consciência dos sujeitos singulares mediante o reflexo do mundo externo - sempre por meio de uma atividade subjetiva. E, ao realizar essas atividades, os sujeitos ampliam e incorporam os conhecimentos, as objetivações, as experiências, os instrumentos culturais, e tudo isso lhes permite expandir os limites da vida cotidiana, aparentemente fixos por sua condição de imediaticidade. 
Assim, redizemos que a vida cotidiana é inerente à existência, o que implica afirmar que não há existência que não tenha vida cotidiana. Ela é fundamental para viver nossa vida de necessidades e possibilita - em termos bastante complexos de orientação à superação de patamares que podem e devem - nortear atividades cada vez mais complexas e possíveis a partir de esferas como a arte, a ciência e a filosofia, que explicam, de forma mais apurada e detida, as compreensões vulgares ou recortadas dos fenômenos tratados nos limites da cotidianidade da vida.

Do mesmo modo, também é importante conceber que essas atividades realizadas pelos sujeitos singulares se internalizam por meio da atividade do reflexo e se complexificam a partir de processos internos que se encontram sempre sob influxo das causas externas que repercutem na vida cotidiana. Esses sujeitos também se constituem pelos conhecimentos de objetivações superiores que a educação sistematizada e também não sistematizada pode vir a favorecer, que se expressam no pensamento cotidiano e nos conhecimentos cotidianos de maneira mediada e, na maioria das vezes, são simplificados e recortados pela praticidade imediata da vida. Cabe registrar que simplificados não é resultado de um processo de alta complexidade; entretanto, agir de forma pragmática torna-se necessário, uma vez que ficaríamos alucinados se tivéssemos que, a cada ação de nosso cotidiano, pensar e agir de forma complexa e teórica. Em nosso cotidiano, realizamos uma série de tarefas e ações que se mostram aparentemente muito simples, mas, quando analisadas mais detidamente, revelam enorme complexidade, haja vista serem elas demarcadas por processos de conhecimento desenvolvidos ao longo da história, resultados das mais diversas áreas do conhecimento, como a arte, a ciência, a filosofia, etc.

Essa questão das diversas áreas do conhecimento é fundamental para a formação humana, já que a praticidade necessária ao cotidiano da vida não permite o aprofundamento dos conhecimentos que nos levariam aos nexos e à gênese da constituição dos fenômenos. Se tal aprofundamento não acontece (como pretende uma perspectiva superficial e aligeirada de educação e formação), sobrevivese com apenas arestas de pressupostos, supostos e preconceitos amarrados a um tempo que não outorga a reflexão imprescindível para a compreensão do mundo objetivo, onde, é importante assinalar, não deixam de acontecer as decisões dos sujeitos. Ao contrário, elas são tomadas constantemente a partir das alternativas possíveis e também limitadas ao cotidiano, que se apresenta sempre como um mundo fechado. 
Esse movimento da práxis cotidiana, explicitado anteriormente, é fundamental, mas "não avisa", "não adverte" sobre a existência de mediações dos fenômenos, tampouco sobre outras possibilidades de decisão ou alternativas para ver e avaliar tendencialmente as possíveis consequências das decisões a serem tomadas com base na projeção que os conhecimentos e as experiências permitem.

Assim, permanecer apenas no limiar da vida cotidiana, acreditando, na maioria das vezes, que o mundo é assim e não apresenta outras possibilidades e alternativas de ser diferente, e muito menos de incorporar a ideia de que é possível realizar escolhas que permitam processos de superação, favorece a mera adaptação sem questionamentos, uma vida cotidiana acrítica, e só podemos realizar uma reflexão crítica da vida quando acessamos dimensões estéticas, filosóficas, científicas mediante os processos de objetivações superiores.

Entendemos que, sem os processos de objetivação superiores, os sujeitos ficam restritos a um sistema de crenças que está fortemente influenciado pelas esferas religiosa e moral, que não permitem a explicação dos fenômenos pela via desses conhecimentos. Afinal, conhecer, explicar e entender trazem consigo a possibilidade de mudança de posição, implicando questionamento e crítica. É nesse ponto que os processos educativos, a formação e a didática, entre outros, enquanto espaços possíveis de mediação entre o conhecido e o desconhecido, podem favorecer a realização de saltos qualitativos para ampliação constante dos limites estreitos desse cotidiano, que não desaparece (nem poderia), mas que pode ser bem mais extensivo e profundo do que a permanência e superficialidade do cotidiano.

Nesse sentido, ao expressar o termo cotidiano escolar, entendemos que não existe "um cotidiano escolar e uma vida cotidiana", o que existe é apenas e tão somente uma vida cotidiana - nos termos expressados acima - que inclui uma série de atividades e tarefas que podem nos aproximar ou afastar dela. Portanto, vamos considerar que a vida cotidiana da escola expressa um cotidiano (enquanto ser da escola, forma determinada de sua existência) e que nele se definem atividades próprias e específicas. Uma dessas atividades é a transmissão do conhecimento elaborado pela humanidade, às gerações mais novas, parte necessária da reprodução social que acontece a partir de múltiplas mediações e desdobramentos em diversas dimensões já citadas anteriormente, envolvendo sujeitos formados para essa atividade, projetos político-educacionais, processos políticos, relação entre diferentes áreas do conhecimento a partir de currículos que promulgam concepções de conhecimento e conteúdo cujo ensino julga-se necessário, entre outras.

Além do exposto, gostaríamos de apontar uma posição já destacada em outros textos ${ }^{12}$, relativa aos conhecimentos cotidianos, aos conhecimentos científicos e ao que chamávamos, naquele momento, PERSPECTIVA, Florianópolis, v. 35, n. 3, p. 996-1012, jul./set.. $2017 \quad$ http://www.perspectiva.ufsc.br 
de dimensão cotidiana da escola. Nessa posição, ainda não identificávamos diferenças entre cotidiano escolar e vida cotidiana, tendo em vista que nos limitávamos a dizer que, "em relação ao cotidiano escolar e à dimensão cotidiana do conhecimento, consideramos que são duas dimensões que, a nosso entender, se confundem" (TORRIGLIA, 2008, p. 30). Dessa maneira, tomávamos a categoria cotidiano escolar sem questioná-la nem a diferenciar da vida cotidiana, diferentemente do que fazemos no presente texto. A mudança, portanto, representa um avanço em nossa compreensão sobre o aprofundamento dos nexos e da estrutura da vida cotidiana. É importante destacar que isso não significa um recuo à discussão em relação ao conhecimento e às suas dimensões - cotidiano, espontâneo e teórico/cientifico -, ao contrário, é um avanço na compreensão em relação à dimensão cotidiana da vida escolar e da vida cotidiana.

Continuamos considerando que houve (ainda há, talvez?) nas práticas escolares - por um amplo processo de descuido e desvalorização da teoria e da adoção de um tipo de conhecimento superficial/pragmático - uma confusão visível sobre quais conhecimentos a escola deveria transmitir (e aqui ingressa a questão dos conhecimentos cotidianos e científicos). Expressamos, naquele momento, que o conhecimento cotidiano é inerente ao ser, mas insuficiente quando se limita e se restringe ao pequeno mundo e, assim, insistíamos em defender que, nos processos de ensino e de aprendizagem em instituições educacionais, especialmente nas escolas, tornava-se imprescindível destacar aquilo que era nosso principal pressuposto: a existência do cotidiano escolar não é diretamente proporcional ao conhecimento cotidiano.

Queríamos e queremos frisar que julgamos haver uma compreensão equivocada em relação ao ensino, ao cotidiano e ao conhecimento. Pensamos que esse equívoco diz respeito à ideia de que os processos de ensino e de aprendizagem deveriam estar pautados a partir do cotidiano escolar e que, portanto, esses conhecimentos também deveriam ser cotidianos. Essa formulação nos levou a questionar e pensar que a dimensão do conhecimento cotidiano, o pensamento cotidiano, é parte inerente e insuprimível do conhecimento mais elaborado, mas, como indicamos acima, não é diretamente proporcional a ele.

Esta ideia nos remete a dois apontamentos que merecem ser destacados, dados os avanços teóricos de nossos estudos. Assim, temos por um lado: o fato de a vida cotidiana da escola e dos sujeitos nela envolvidos expressarem suas especificidades e os movimentos necessários para sua existência não significa que os conhecimentos originados desse movimento tenham que ser 
necessariamente os conhecimentos a serem transmitidos pela escola, isto é, confundidos com os conhecimentos cotidianos ${ }^{13}$ que estudantes e professores possuem, os quais, com suas próprias vidas cotidianas singulares, envolvem-se na vida cotidiana da escola. Por outro lado, como consequências do antedito, um dos lugares em que acontece a transmissão do conhecimento elaborado é a escola e é nela que deve ser ensinado esse conhecimento, a partir da dialética entre ambos os conhecimentos, o conhecimento cotidiano e o conhecimento mais elaborado (científico, filosófico, estético).

Destarte, a escola deixa de ter uma vida cotidiana? Não. Os sujeitos que fazem parte do cotidiano escolar deixam sua vida cotidiana na porta da escola? Claro que não. Então, a questão é: como os conhecimentos mais elaborados retornam à vida cotidiana dos sujeitos mediante o ensino, mediante a transmissão do conhecimento sistematizado, que é uma das características da escola?

Vejamos algumas aproximações. Se pensarmos que os conhecimentos mais complexos surgem do solo da vida cotidiana e do pensamento cotidiano, e que os contínuos processos de complexificação (objetivações) permitem sua elevação, também compreenderemos que essa complexificação se dá pelo contínuo retorno desses conhecimentos à vida cotidiana. Cabe destacar, e é fundamental para nós, que essa afirmação tem por base uma concepção dialética e materialista da realidade, entendendo que não se pode ignorar o desenvolvimento dos processos cognitivos e consequentemente a formação das funções psicológicas superiores dos homens, as quais permitem uma apropriação a mais adequada possível da realidade. Não por acaso, Lukács (1966, p. 17) vai dizer que a realidade e seu reflexo e reprodução mental [...] é uma unidade dialética de continuidade e descontinuidade, de tradição e revolução, de transições paulatinas e saltos [...]". Nesse movimento, insere-se a dialética de ambos os conhecimentos.

Nesse contexto, não saímos da vida cotidiana como se fosse uma etapa a ser superada; ao contrário, estamos sempre dentro dela, e aí o local onde se produzem os processos de objetivação - dos mais simples aos mais complexos. Quanto mais ricos e profundos são os conhecimentos que impactam e questionam esse patamar da vida, maior será a ampliação e a ruptura dos limites que caracterizam a vida cotidiana. O que se supera são as concepções limitadas e os preconceitos que acompanham o caráter imediato da vida cotidiana, fazendo com que se ampliem e permitam uma compreensão mais apurada da realidade, revelando mediações antes não percebidas (o que não significa que não existam).

Aqui se configura um dos aspectos que fundamentam a indissociabilidade, na práxis, da cotidianidade e do processo de complexificação das objetivações genéricas na vida cotidiana. Por isso, consideramos fundamental entender o que Lukács (1966, p. 4) explica: “[...] o fato de que a origem de PERSPECTIVA, Florianópolis, v. 35, n. 3, p. 996-1012, jul./set.. $2017 \quad$ http://www.perspectiva.ufsc.br 
nossas representações ontológicas está na cotidianidade não significa que podem e devem ser aceitas acriticamente". Ao contrário, o autor explica que "[...] tais representações são repletas não apenas de preconceitos ingênuos, mas com frequência de ideias manifestamente falsas que, se às vezes provêm da ciência, nela penetram, sobretudo a partir das religiões, etc. [...]"14. Esses preconceitos e manifestações falsas sobre a realidade convivem (por assim dizer) em nossa vida cotidiana, mas, também a partir de processos de rupturas e aprofundamentos conceituais sobre o momento histórico contemporâneo, é plausível apreender e aprender, questionar as compreensões limitadas e tensionar as ideias preconcebidas para aprimorar essa primeira etapa do entendimento, que necessariamente ocorre por meio do pensamento intuito-perceptivo, possibilitando, assim, a extensão e ampliação do conteúdo da vida cotidiana. Esses movimentos também nos permitem realizar escolhas não meramente adaptativas, que incluam outras dimensões e níveis de decisão que podem nos orientar ao "reino da liberdade" em sua relação com o "reino da necessidade", que obviamente não pode ser eliminado.

Por isso, Lukács assinala que a necessidade de crítica - que se apreende com elaborações conceituais complexas - não autoriza descuidar do fundamento cotidiano, o "[...] prosaico e terreno intelecto do cotidiano, alimentado pela práxis diária, pode de quando em quando constituir um saudável contrapeso aos modos de ver estranhados da realidade das esferas "superiores" (LUKÁCS, 1966, p. 4).

A vida cotidiana da escola é um lugar (relação de relações) em que acontecem os processos de transmissão de conhecimento, com todas suas contradições e dimensões, mas conhecer transcende os interstícios e os limites desse "espaço-tempo", já que no processo de conhecer ingressam - a partir dos sujeitos formados e em formação, a partir dos professores e estudantes, a partir da organização social do currículo - constantemente os conhecimentos históricos da vida humana. Já assinalamos que a dimensão do conhecimento tem sua gênese e explicação a partir da compreensão da importância do papel da consciência e das formas de reflexo que nela se desenvolvem no movimento de compreensão do real. O "impulso vital a conhecer" é uma questão que está posta na vida em sua totalidade, é inerente a ela, e no solo da vida cotidiana essa necessidade de "saber mais" "de conhecer mais" vai muito além dos confins do pequeno mundo (que não deixa de existir porque se amplia), seja na plenitude da vida, seja nos interstícios da escola, por onde a vida também se expressa em sua plenitude enquanto atividade e elaboração humana. 


\section{Para finalizar... Novas perguntas, outras pesquisas...}

A partir da abordagem realizada, asseveramos a premissa de que o conhecimento está atravessado e organizado por múltiplas dimensões e mediações e que o ser do conhecimento é uma categoria complexa e mediada que produz e reproduz a dinâmica do social e as possíveis alternativas/escolhas expressas em projetos socioideológicos que sustentam a sociabilidade, em nosso caso, a capitalista. Bem destaca Heller (1991) que a reprodução do homem particular é sempre uma reprodução histórica, a reprodução de um particular em um mundo concreto. Desse modo, a vida cotidiana tem uma história, ela muda ou se transforma com a dinâmica social. Parafraseando Lukács,

Heller afirma que o primário é a conduta do homem na vida cotidiana, o comportamento cotidiano. É nesse sentido que Heller assinala que a vida cotidiana é "um espelho" e "um fermento secreto da história" (HELLER, 1991, p. 20). E a história é o agir humano, a atividade humana, nada mais que o humano em movimento na vida.

Reconhecemos, como Lukács, que “o comportamento cotidiano do homem é, ao mesmo tempo, o começo e o final de toda atividade humana", e entendemos e defendemos que este comportamento "se enriquece constantemente com os supremos resultados do espírito humano, assimila-os a suas cotidianas necessidades práticas e assim dá lugar, como questões e como exigências, a novas ramificações das formas superiores de objetivação" (LUKÁCS, 1966, p. 11-12).

Nossa pergunta e nosso mote de pesquisa derivam, então, na seguinte questão: como entender, a partir da vida cotidiana, o processo da transmissão de conhecimentos mais complexos e elaborados nos processos educacionais? Como identificar o movimento dos conhecimentos mais elaborados e seu retorno à vida cotidiana? Qual seria o papel da educação e, em especial, do campo da didática? Essas são questões que demandam um longo processo de investigação e fazem parte de uma pesquisa em andamento que nos desafia a continuar discutindo esse tema tão relevante para os processos de formação humana e a atividade docente.

Como indicamos acima, o processo de descuido e de desvalorização da teoria e a adoção de um tipo de conhecimento superficial/pragmático por parte das instituições escolares permite-nos formular uma hipótese inicial sobre o papel da didática: junto com esse movimento de desvalorização da teoria, a didática sofreu um esvaziamento de seu papel e de sua função, trazendo consequências para a 
transmissão dos conhecimentos elaborados, assim como para o processo de apropriação e compreensão da realidade, tão imprescindível para a intervenção e a transformação social.

Notas

${ }^{1}$.Ressaltamos que a apropriação do conhecimento assenta-se na base ontológica. Entretanto, é impossível menosprezar as dimensões epistemológicas e gnosiológicas desse processo, porque sob a base ontológica há sempre relações de conhecimento e de funcionamento da apreensão do ato de conhecer. Nesse sentido, existe uma dialeticidade entre essas dimensões, que, em nosso entendimento, favorece o conhecimento do mundo objetivo e, de maneira crítica, orienta os processos possíveis de intervenção.

${ }^{2}$.A reprodução é entendida aqui no sentido ontológico, não de forma mecânica, mas com base em processos de conservação e continuidade.

3 “'O ponto mais frágil da Agenda Pós-moderna e seu mais evidente pomo de discórdia: considerar as complexas determinações das forças históricas uma metanarrativa e, ao desprezálas, reduzir a uma narrativa sobre o único e o contingente.” (MORAES, 2004, p. 342). Cf. também: MORAES, Maria Célia. "Os "pós-ismos" e outras querelas ideológicas. Perspectiva, Florianópolis, v. 14, n. 25, p. 45-60, jan./jun. 1996.

4 Viemos, desde 2104, desenvolvendo a pesquisa teórica intitulada Ontologia crítica, vida cotidiana e as dimensões do conhecimento: primeiros apontamentos para discutir o ser da didática (CED/PPGE/UFSC).

${ }^{5}$.Cf. TORRIGLIA, Patricia Laura; CISNE, Feiten Margareth. A grande ausente na contemporaneidade: a possibilidade da crítica ontológica na formação docente e os processos de conhecimento. In: ENCONTRO SOBRE TRABALHO DOCENTE E FORMAÇÃO, 2. Políticas, Práticas e Investigação: pontes para a mudança. Porto, Portugal, 1-3 nov. 2013. Anais... Porto: CIIE, 2014. p. 2488-2453, v. 1.

${ }^{6}$.Na base desses processos encontra-se uma infinidade de movimentos e conexões psíquicas. No entanto, destacamos que a sensação e a percepção lhes são constitutivas e, como já afirmamos acima, estas também possuem graus e dimensões dentro de cada um desses processos (análise, síntese, generalização e abstração).

${ }^{7}$.LUKÁCS, G. Para uma Ontologia do Ser Social. São Paulo: Boitempo, 2013.

${ }^{8}$ A cozinheira de Molière, na obra $O$ Doente Imaginário, é uma personagem que sabia tudo e tinha o controle de tudo.

${ }^{9}$.As generalizações ocorrem por meio da atividade do reflexo, realizada pelo pensamento por intermédio da consciência dos seres singulares, as quais, ao capturar as cadeias causais presentes no mundo objetivo, permitem realizar novas elaborações e generalizações que lhe possibilitam novas ampliações e diferentes objetivações.

10 "Apenas a mencionamos para mostrar que a reprodução social de fato se realiza, em última análise, nas ações dos homens singulares - a realidade do ser social se manifesta de modo imediato no homem -, mas essas ações a serem realizadas forçosamente se encaixam uma na outra para formar complexos de relações entre os homens, que, tendo surgido, possuem certa dinâmica própria, isto é, não só existem, se reproduzem e se tornam socialmente operativos independentemente da consciência dos homens singulares, mas também proporcionam impulsos mais ou menos, direta ou indiretamente, decisivos para as decisões alternativas." (LUKÁCS, p. 182, 2013). 
${ }^{11}$.Para maiores esclarecimentos sobre os recuos teóricos, indicamos: MORAES, Maria Célia Marcondes de. Recuo da teoria. In: . Iluminismo às avessas. Rio de Janeiro: DP\&A, 2003. TORRIGLIA, Patrícia Laura; MORAES, Maria Célia Marcondes de. Educação light? Que palpite infeliz. Indagações sobre as propostas do MEC para a formação de educadores. Teias, Revista da Faculdade de Educação/UERJ, ano 1, n. 2, jun./dez., 2000. DUAYER, Mario. Antirrealismo e absolutas crenças relativas, Margem Esquerda - ensaios marxistas, v. 8, p. 109-130. São Paulo: Boitempo, 2006.

${ }^{12}$.Cf. TORRIGLIA, Patricia Laura. Currículo; algumas reflexões sobre as dimensões do conhecimento. In: CARVALHO de CARVALHO, Diana; GRANDO, Beleni; BITTAR, Mariluci (Orgs). Currículo, diversidade e formação. Florianópolis: EdUFSC, 2008.

${ }^{13}$.Os conhecimentos cotidianos são fundamentais para o sujeito se movimentar no mundo, eles fazem parte do movimento de ingresso deste novo sujeito na realidade, estão presentes principalmente na infância temprana, neles está contido o fermento que mobilizará o sujeito a sair da mera funcionalidade dos objetos e das ações cotidianas (necessárias) e buscar o conhecimento mais elaborado, que se encontra subjacente a esta primeira aproximação e entendimento da realidade. Vigotski (2001) dedicou-se a analisar, em seu livro A construção do pensamento e da linguagem, no capitulo sexto, intitulado Estudo do desenvolvimento dos conceitos na infância, esta importantíssima questão para a formação do conceito científico, concluindo que a base do conceito científico encontra-se no conhecimento cotidiano, são as questões colocadas pelo cotidiano, pela vida prática dos sujeitos, que os fazem buscar respostas e conhecimentos mais elaborados para solucionar suas necessidades.

14 “"...] a filosofia pode e deve exigir apenas que cada ciência não incorra num antagonismo com a peculiaridade do ser, cujas leis ela está tentando desvelar. Como sabemos, Hartmann apontou, nesse ponto, muito acertadamente para a importância da intentio recta, que leva do cotidiano até a filosofia, passando pela ciência, em contraposição à intentio obliqua da gnosiologia e da lógica, ainda que, como expusemos a seu tempo, a sua crítica nessa questão nem sempre tenha sido suficientemente concreta e consequente" (LUKÁCS, 2013. p. 457). 


\section{Referências}

AGUIAR, A. Direitos Humanos e Emancipação: uma aproximação da ontologia lukacsiana. 2011. 232f. Tese (Doutorado em Direito) - Programa de Pós-Graduação em Direito da Universidade Federal de Santa Catarina, Florianópolis, 2011.

CISNE, F. M., TORRIGLIA, P. L. Processo de produção e de apropriação do conhecimento: o papel da atividade como prioridade ontológica. In: Educação em Perspectiva, v.3, n. 2, p. 263-281, jul./dez. 2012.

CISNE, F. M., TORRIGLIA, P. L. A grande ausente na contemporaneidade: a possibilidade da crítica ontológica na formação docente e os processos de conhecimento. In: ENCONTRO SOBRE TRABALHO DOCENTE E FORMAÇÃO, 2. Políticas, Práticas e Investigação: pontes para a mudança. Porto, Portugal, 1-3 nov. 2013. Anais... Porto: CIIE, 2014. p. 2488-2453, v. 1.

HARTMANN, N. Ontologia. I Fundamentos. México - Buenos Aires: Fondo de Cultura Económica. 1954.

HELLER, A. Sociología de la Vida Cotidiana. 3. ed. Barcelona, Espanha: Península, 1991.

LUKÀCS, G. Estética: la peculiaridad de lo estético. Barcelona, Espanha: Grijalbo, 1966.

LUKÁCS, G. As Bases Ontológicas do pensamento e da atividade do homem, Revista Temas de Ciências Humanas, São Paulo, 1978, p. 1-17. Tradução: Carlos Nelson Coutinho. (Conferência redigida para ser apresentada ao Congresso Mundial de Filosofia em Viena em 1968 e publicada em 1969 em Húngaro).

LUKÁCS, G. Para uma Ontologia do Ser Social II. Tradução: Nélio Schneider, Ivo Tonet, Ronaldo Vielmi Fortes. São Paulo: Boitempo, 2013.

RUBINSTEIN, S. L. El Proceso del Pensamiento. Havana, Cuba: Editora Universitária, 1966.

RUBINSTEIN, S. L. El Desarrollo de la Psicologia: princípios e métodos. Havana, Cuba: Pueblo e Educación, 1979.

TORRIGLIA, P. L. Reflexões sobre o trabalho e a reprodução social: primeiras aproximações em relação ao complexo educativo. 1999. 167f. Dissertação (Mestrado em Educação) - Universidade Federal de Santa Catarina, Florianópolis, 1999. 
TORRIGLIA, P. L. Currículo: algumas reflexões sobre as dimensões do conhecimento. In: CARVALHO de CARVALHO, D. GRANDO, B.; BITTAR, M. (Org.). Currículo, Diversidade e Formação. Florianópolis: EdUFSC: 2008.

VIGOTSKI, L. S. A construção do pensamento e da Linguagem. São Paulo: Martins Fontes. 2001. 


\section{Does Daily Life in School Express Everyday life? Ontological approaches in debate}

\begin{abstract}
This conceptual theoretical text discusses, based on an ontological criticism, knowledge production, the processes of knowing, teaching and learning, and the ontological foundations that consolidate these processes. We affirm the pre-existence of an objective world, independent from our consciousness, which considers that it has a material basis that sustains it and allows - through this procedural and historical materiality - this consciousness to establish objective knowledge, of itself that is, an intelligibility of this world. The work is based on studies of the dialectical-materialist perspective of history, found in the work of Lukács, Rubinstein Sheptulin and Heller, and the work of education that we have conducted with the Group of Research and Study in Critical Ontology. We first approach some questions about knowledge and its appropriation from the above mentioned point of view. We then deepen the understanding of the concepts of daily school life and everyday life, creating a tension between their contents, their forms of transmission and appropriation, and their relationship with didactics. We conclude by presenting questions for further investigations.
\end{abstract}

Keywords: Everyday life. Appropriation of knowledge. Critical ontology.

\section{Patricia Laura Torriglia}

E-mail: patrilaura@gmail.com

Margareth Feiten Cisne

E-mail: margacisne@gmail.com

\section{¿La vida cotidiana de la Escuela expresa un cotidiano? Aproximaciones ontológicas en debate.}

\section{Resumen:}

El presente texto de naturaleza teórica conceptual discute, a partir de la ontología crítica, la producción de conocimiento, los procesos de conocer, enseñar y aprender, como también las bases ontológicas que consolidan eses procesos. A partir de nuestros estudios basados en la perspectiva del materialismo histórico-dialéctico - Lukács, Rubinstein Sheptulin e Heller - y del trabajo de formación que venimos desarrollando junto al Grupo de Estudios e Investigación en Ontología Critica GEPOC, defendemos como premisa preliminar la preexistencia del mundo objetivo independiente de nuestra consciencia, que implica considerarlo como poseedor de una base material que lo sustenta y le permite, por medio de esa materialidad, que es procesual e histórica, establecer un conocimiento objetivo sobre si, significando esto, la inteligibilidad del mundo. En esa dirección, en un primer momento, abordamos algunas cuestiones sobre el conocimiento y su proceso de apropiación a partir de la base supra citada. Posteriormente profundizamos el concepto de cotidiano escolar $\mathrm{y}$ vida cotidiana, sus contenidos y su forma de transmisión y apropiación de los conocimientos y la relación con la didáctica. Finalizamos presentando cuestiones que nos posibilitan nuevas líneas de investigación.

Palabras claves: Vida Cotidiana. Apropiación del conocimiento. Ontología Critica

Enviado em: 29/09/1016

Versão final recebida em: 26/09/1017

Aprovado em: 19/10/2017 